\title{
A POLÍTICA DO CONTRABANDO NEGREIRO
}

\author{
PARRON, Tâmis. A política da escravidão no Império do Brasil, 1826- \\ 1865. Rio de Janeiro: Civilização Brasileira, 2011. 373 p.
}

Como o título sugere, o livro de Tâmis Parron tem como proposta demonstrar o estreito vínculo que unia o Estado nacional brasileiro, em formação, com a manutenção e o incremento da escravidão como meio de desenvolvimento econômico e civilizacional do País, em especial do Sudeste cafeeiro. Fruto de sua dissertação de mestrado em História (USP), defendida em 2009, o trabalho supera de longe as exigências comuns a este nível de formação. A obra abarca um longo período da história do Império brasileiro, o que certamente exigiu do autor um esforço na reconstituição e análise de eventos e conjunturas. As balizas temporais foram escolhidas a partir de dois marcos que anunciam, respectivamente, o início e o fim da política da escravidão no País: um interno - a instalação definitiva do Parlamento no Brasil Imperial (1826), que também coincide com $\mathrm{o}$ ano do tratado anglo-brasileiro que definiu o fim do tráfico, em 1831; e o outro externo, a abolição da escravi- dão nos Estados Unidos (1865), àquela altura principal esteio do sistema escravista mundial e espelho para as ações da classe dirigente brasileira.

As principais fontes utilizadas na pesquisa são aquelas que normatizaram e regularam o exercício da política no Brasil imperial, tais como os mais de cem volumes dos Anais da Câmara dos Deputados e do Senado; além de livros, panfletos, memórias, traduções, artigos de jornal, correspondência diplomática, atas e pareceres do Conselho de Estado, petições coletivas (representações) de proprietários, de câmaras municipais e assembleias provinciais. Uma preocupação constante no trabalho - e de cara um de seus méritos - é o esforço de contextualizar o Império brasileiro nas conjunturas local e global. Aliás, o livro é aberto com a exposição cuidadosa de "dois fenômenos de longa duração", tidos por Parron como pressupostos constantes na análise de todo o trabalho: a economia-mundo de livre mercado e o sistema interes- 
tatal moderno do liberalismo político (p. 23).

Tâmis Parron defende que é possível notar a vigência de uma política pró-escravidão ao longo da trajetória de formação do Estado nacional, embora não com a intensidade e mesmo virulência que se deu nos Estados Unidos, divididos entre norte livre e sul escravista. Demonstrar que no Brasil também houve um esforço político e intelectual pró-escravista é um dos principais, talvez o mais importante, objetivo do livro. No entendimento de Parron, esta política da escravidão aqui vista como uma rede de alianças atuando em favor da estabilidade institucional do cativeiro - foi marcada por duas fases intimamente imbricadas: a política do contrabando negreiro, seguida da política da escravidão na era pós-contrabando.

A demonstração desta ideia mestra é feita em quatro capítulos. O primeiro denomina-se "Soberania, ordem social e escravidão, 1826-1835". Embora o marco inicial do estudo seja o ano de 1826, portanto já no período pós-Independência, o autor recua ao período joanino (1808-1821) para demonstrar que foi ali "que se formou uma nítida política da escravidão, dotada de um protocolo de discurso e de um protocolo de ação, ainda que executados na lógica do Antigo Regime" (p. 44). Essa política foi forjada a partir do momento em que d. João VI e seus apoiadores decidiram permanecer no Brasil, parte mais próspera do Império luso, e enfrentar as pressões inglesas para abolir o tráfico africano - decisão esta que, como sabemos, provocou a Revolução do Porto (1820) e, em seguida, a própria separação do Brasil. A ascensão de d. Pedro I como imperador sob uma monarquia constitucional não implicou na automática conversão ou continuidade da política escravista joanina numa política escravista imperial. Pelo contrário, segundo Parron, naqueles conturbados anos de disputas entre os poderes Legislativo e Executivo, e de forte pressão britânica pela abolição do tráfico, o que predominou foi a vontade do imperador e seus apoiadores, que fizeram o parlamento referendar, em 1827, a Convenção de 8 de novembro de 1826 , que previa a abolição do trato negreiro num prazo de três anos, tipificando o contrabando em crime de pirataria. Esta medida, somada a outros fatores, levou d. Pedro a abdicar do trono, em abril de 1831, quando então o Brasil passou por importantes reformas, a começar pela forma de governo: a Regência. Nessa nova fase, além da reforma constitucional, de 1834, seria também aprovada a Lei 7 de novembro 1831 que declarava, em seu artigo primeiro, serem livres os africanos importados pelo Brasil a partir daquela data.

E aqui finalmente chegamos ao ponto alto do capítulo. Para Tâmis 
Parron, a Lei de 1831 não foi feita apenas para "inglês ver", como avaliaram Caio Prado Júnior, Robert Conrad, Emília Viotti da Costa, José Murilo de Carvalho e, mais recentemente, Jeffrey Needell, entre muitos outros. Prova disso é que, na primeira fase do tráfico negreiro ilegal, entre 1831 e 1834, "entraram no Brasil cerca de 40 mil escravos - o equivalente a apenas $6 \%$ do total contrabandeado entre 1831-1850" (p. 173). Alinhado a autores como Jaime Rodrigues e Beatriz Mamigonian, para quem a lei exerceu "a função política de reafirmar a soberania nacional”, Parron defende ainda que o diploma de 1831 pode ser entendido "como exercício probatório de autonomia dos órgãos representativos" (p.85), no caso, o Parlamento, outrora desrespeitado no período 1826-27. Ao conceber a Lei de 1831, os parlamentares simpáticos aos ideais antiescravistas apostavam verdadeiramente no declínio e logo extinção do comércio negreiro, ainda mais se levarmos em conta o crescimento do abolicionismo inglês e a ocorrência de eventos importantes, como a revolta dos malês, em 1835 - cuja dimensão política antiescravista é fartamente comprovada por "notícias de jornal" e pela repercussão no Parlamento e na Assembleia Provincial baiana, derivando a proposição de "projetos de lei e de um tratado internacional" (p. 103) - como, aliás, João José Reis já havia indicado em sua obra. ${ }^{1}$ Por tudo isso, Tâmis Parron conclui que,

no início da Regência, uma tendência antiescravista dos parlamentares, especialmente sensíveis às insurreições dos cativos, atuou de maneira expressiva contra interesses da fração da classe senhorial desejosa de reabrir o tráfico sobre a forma de contrabando (p. 101).

Ainda que se manifestassem argumentos escravistas no intervalo 1826-1835, não se pode dizer que houvesse ali uma política da escravidão instalada no Estado.

Contudo, ainda em 1835, no contexto das eleições para a Regência Una, o padre Diogo Antônio Feijó percebera que, assim como a economia cafeeira, os ventos políticos estavam mudando. Montando uma estratégia de campanha "impecável”, o outrora ministro da Justiça publicou o artigo "Do tráfico dos pretos africanos" que, segundo Parron, "pode ser entendido como a primeira resposta de um político célebre à iminente recidiva do tráfico negreiro", haja vista que as ideias ali expressas beneficiavam o incremento do comércio de almas "sem por em grande risco a segurança pública do Império" (p. 132). Vencido o pleito eleitoral,

\footnotetext{
João José Reis, Rebelião escrava no Brasil: a história do levante dos malês em 1835, São Paulo: Companhia das Letras, 2003, especialmente a parte IV.
} 
seu governo - cujos ministérios, "nascidos de amplas coalizões, abrigavam homens notoriamente dispostos a perseguir traficantes" (p.134) - acabou por distanciar-se da política pró-contrabando desejada pelos escravistas do Vale do Paraíba -, embora se possa notar um significativo aumento do tráfico já a partir daquele ano. ${ }^{2}$

Por isso a reação daqueles que eram favoráveis ao contrabando e à escravidão não tardou a chegar. Esta resposta conservadora - bem que se diga, toda ela exercida através dos canais de instituições liberais recentemente implantadas, como o Parlamento e a imprensa - é justamente o objeto central do segundo capítulo, denominado "Regresso e a política do contrabando negreiro, 1835-1841". Partindo da premissa segundo a qual o tráfico negreiro dificilmente poderia reaparecer na forma de contrabando intenso sem a anuência articulada de autoridades e estadistas imperiais, Parron examina como os líderes do Regresso, notadamente Bernardo Pereira de Vasconcelos, reagiram à Lei de 1831. Motivados pelo crescimento do consumo do café no mercado mundial, os líderes políticos da região do Vale do Paraíba partiram para o

Em 1834 entraram no Brasil aproximadamente 18.100 africanos, 37.134 em 1835 , 52,837 em 1836, e 56,769 em 1837. Ver The Trans-Atlantic Slave Trade Database, disponível em www,slavevoyages.org. Acesso em 24 de março de 2012. combate sistemático da mencionada lei, defendendo obstinadamente sua revogação. Esta "nova política" foi consolidada, sobretudo, a partir da renúncia de Feijó seguida da ascensão, em 1837, do "partido do regresso" e seu núcleo ideológico, também conhecido como "partido da ordem" e "partido saquarema". Segundo Parron, pela primeira vez se percebe a ação concertada de líderes políticos e de grandes proprietários rurais (do norte da província fluminense, do Vale do Paraíba do Rio de Janeiro e de São Paulo, da Zona da Mata mineira e também da Bahia e de Pernambuco) em torno da liberação do contrabando negreiro e do crescimento da escravidão. Para concretizar esses intentos, o Regresso tinha dois pontos de pauta principais: a interpretação do recém-aprovado Ato Adicional (1834) e a reforma do Código de Processo Criminal (1832), ambos visando centralizar o Judiciário; e a defesa, não só do contrabando, mas também da propriedade escrava ilegal dele resultante. Com o controle do Judiciário e da polícia nas mãos dos ministros da Justiça e do Império, os regressistas puderam dar tranquilidade aos fazendeiros e seus representantes de que não fechariam o tráfico negreiro. Aqui, o autor já nota a conformação de uma política da escravidão-ou, mais precisamente, política do contrabando negreiro. Feitos estes ajustes legais, Parron 
demonstra com muita acuidade e riqueza de detalhes como

os líderes do Regresso sustentaram em bloco a reabertura do contrabando nos mais diversos meios de atuação: nos jornais, no Parlamento, nas decisões do executivo, na elaboração de projetos de leis, na publicação de opúsculos, no patrocínio de livros, no envio de representações municipais e provinciais (pp. 136-137).

A partir de então, passariam a traçar os desígnios da escravidão no País, conforme o capítulo terceiro, intitulado "Grã-Bretanha, hegemonia saquarema e contrabando: um Brasil todo africano, 1841-1850".

Segundo Parron,

ao longo da década de 1840 , a política do contrabando negreiro condicionou o que poderia ser dito ou silenciado nos espaços públicos, aceito ou negado no centro de decisão do Estado nacional e até mesmo criado ou omitido nos discursos artísticos (p. 208).

Por outro lado, o combate aos antiescravistas se fez por meio de outra estratégia que não a censura ou a repreensão. Assim, no lugar de campanha pública de revogação da Lei de 1831, os saquaremas conceberam o projeto de terras devolutas (1842), com o fito de atrair para cá africanos livres. Aqui, Parron vai na contramão da historiografia ao destacar que a primeira opção era pelos africanos e não necessariamente pela imigração europeia. Assim, como acontecerá em relação ao fechamento do tráfico atlântico, tal plano só não se concretizaria por conta da oposição britânica em permitir a vinda de africanos, livres ou escravos, para o o Brasil.

Outro ponto controverso é a interpretação que o autor dá para o fechamento do tráfico africano em 1850 . No seu entendimento, eventos como a insurreição quilombola de Vassouras (1838), os rumores da década de 1840, os planos revoltosos do Vale do Paraíba (a chamada Conspiração de 1848) e a crise em torno dos africanos livres (1849/1850), em nada contribuíram para o fim de contrabando negreiro, conforme argumentam autores como Robert Slenes, Sidney Chalhoub e Dale Graden, entre outros. Para não dizer que Parron, à semelhança de Jeffrey Needell, ${ }^{3}$ não vê nenhuma consequência política mais ampla nas ações de resistência escrava, é aberta uma exceção para a revolta dos malês, ainda assim, se considerada no contexto imediato à sua ocorrência, ou seja, em 1835. Em suma, foi a pressão britânica que impeliu os saquaremas a estancar o contrabando de gente - e isto depois de esgotadas todas as tentativas de introdução do braço africano, quer na condição de cativos, quer na de colonos livres.

Jeffrey Needell, The Party of Order: The Conservatives, The States and Slavery in Brazilian Monarchy, Stanford: Stanford University Press, 2006. 
Por sua vez, a supressão do tráfico não decretou o fim da escravidão no Império do Brasil. Ele apenas obrigou os saquaremas a reorientarem a política da escravidão, construindo o que Tâmis Parron chama de "política da escravidão na era pós-contrabando". O quarto e último capítulo, denominado "Coroa e Parlamento: poder político e escravidão na era póscontrabando, 1850-1865", debate em que medida a supressão do tráfico africano alterou a relação de forças políticas no Parlamento e como as lideranças parlamentares (tanto regressistas como ex-regressistas) adotaram os Estados Unidos como referência para a abordagem política da escravidão. Após 1850, a vida política brasileira foi marcada pela relativa tranquilidade e estabilidade das instituições, um período que ficou conhecido por Conciliação. Nesse cenário, foi reinventada uma nova política próescravidão, que visava a "confluência de longo prazo entre imigração espontânea e crescimento do cativeiro à maneira dos Estados Unidos" (p. 312). Embora a historiografia tenha analisado o referido período como a fase de ascendência da figura de d. Pedro II sobre os partidos políticos, Tâmis Parron faz coro com o estudo clássico de Ilmar Mattos ${ }^{4}$ para defender ter-se dado, de fato, a continuidade da supremacia conservadora nos

$4 \quad$ Ilmar R. de Mattos, O tempo saquarema, São Paulo: Hucitec, 1985. desígnios políticos do Império, inclusive em matéria de escravidão. Para Parron, feitos como

moderar a reforma eleitoral, prorrogar a reforma do Judiciário, derrubar um gabinete composto por líderes liberais, centralizar a emissão do papel-moeda e conquistar a legislatura vindoura (1861-1864) (p. 286)

eram provas inequívocas de sua força. Dessa forma, ainda que possamos notar a ação de parlamentares liberais na defesa da continuidade da escravidão na "era pós-contrabando", foram os líderes saquaremas que deram o tom nos debates sobre a conservação da ordem escravista. E isso foi feito a partir de três grandes eixos: i) blindar o Parlamento de discussões sobre o cativeiro; ii) fomentar a imigração livre para obter fonte paralela - e não excludente - de mão de obra barata; e iii) assegurar fluxos estratégicos de cativos, como o tráfico interprovincial, o deslocamento dos escravos urbanos para o campo e o retorno dos que abalavam para as repúblicas vizinhas, onde o cativeiro não gozava de reconhecimento legal" (pp. 287-288).

Em tese, a política da escravidão na era do pós-contrabando consubstanciava-se na melhoria das condições de vida dos cativos e no estímulo de sua reprodução vegetativa como forma de conservar a instituição que, na visão dos escravistas, promovera o desenvolvimento econômico e civilizacional do Brasil. Nesse sentido, 
a Lei de Terras, tal como foi aprovada em 1850, devia ser executada com recursos do governo imperial com o objetivo de estabelecer núcleos de colonos ao lado das grandes propriedades escravistas. Dentro dessa lógica, "o sistema de parceria, talhado para a substituição dos escravos faltantes por trabalhadores livres, devia ser secundário" (p. 311), e não a ação principal, como se ventilou na historiografia existente. Dado o sucesso de semelhante estratégia nos Estados Unidos, o plano parecia perfeito. Porém, segundo Parron, "tal quadro veio a sofrer uma profunda, decisiva e rápida inflexão por causa de um episódio exterior, sobre o qual os agentes sociais brasileiros, fossem proprietários ou políticos, não podiam exercer nenhum controle: a Guerra Civil nos Estados Unidos" (p. 318). Curiosamente, a fonte de inspiração das lideranças conservadoras seria também a força propulsora das ações que romperiam a política da escravidão cautelosamente montada na era do pós-contrabando. Com a ruína da principal potência escravista de então e a crescente onda abolicionista internacional, ficava cada vez mais difícil defender a perenidade da escravidão no Império do Brasil.

Muito bem escrito, A política da escravidão é um livro ao mesmo tempo denso e envolvente, cuja elegância narrativa é por vezes quebrada quando o autor se presta a criticar, a meu ver sem grandes ganhos interpretativos, alguns dos autores de obras clássicas da formação do Estado nacional, como José Murilo de Carvalho e Ilmar Mattos, nos quais, aliás, ele próprio muito se apoiou na construção de suas interpretações. Contudo, estas e outras escolhas de modo algum invalidam o brilho deste livro, que tenho certeza renderá muitos debates historiográficos sobre o assunto de que trata.

Ricardo Tadeu Caires Silva Universidade Estadual do Paraná 